\title{
The Econometric Analysis of the Relationship between the Development of Higher Education and Economic Growth
}

\author{
Jian-Yun $Y U^{1, a,{ }^{*}}$ \\ ${ }^{1}$ Ningbo City College of Vocational Technology, Zhejiang Ningbo China \\ ayujianyun@nbcc.cn
}

Keywords: Higher education, Economic growth, Resident income, Granger test, Cointegration, ECM model.

\begin{abstract}
Economy and education are the two foundations of the development of modern society. The study of the relationship between the two is the key point in the study of educational economics. Generally speaking, the more developed countries, the higher the level of education for residents, the more developed education (especially higher education). Many scholars believe that economic development is the leading cause of the development of education. At the same time, many scholars believe that in the cause and effect of the two, education is the cause and economic development is a result. This paper, from the perspective of quantitative analysis, takes China as an example to explore the relationship between education and economic growth, and establishes the ECM model to describe their dynamic adjustment relations.
\end{abstract}

\section{Introduction}

In the 60s of last century, it was called the "golden age" of the development of higher education in the world. At this stage, as the cornerstone of western traditional education economics, the theory of human capital and the theory of growth in growth economics play an important role in promoting the research of educational economics. The growth economists from theoretical analysis and empirical evidence have demonstrated that the growth of knowledge or accumulation in economic growth has played an important role, so that more countries see the decisive influence of knowledge economy maintained sustained and rapid, steady and healthy growth and technological progress will be generated. However, the greater impetus to the development of post-war higher education should be regarded as a theory of human capital advocated by a series of scholars represented by Schultz. The human capital theory makes a comprehensive and systematic study of the interactive relationship between education development and economic growth from the dual perspective of education and economic development.

The relationship between higher education and economic growth is still mainly concentrated on qualitative analysis, and the quantitative analysis is less. For example, Bin Chen (1996) reviewed the development of the relationship between higher education and economic growth and economic development, and pointed out that people's understanding of the relationship between economy and education has gone from alienation to close transformation. Shaorong Sun, Huiru Yin, Junping Zhu (2001) through the statistical relationship between the countries in the world of higher education level and GDP analysis, mathematical model of the two, and then summed up the enrollment rate of higher education and per capita GNP regression curve showed the first emergency relief after the properties of convex curve.

Different from the research perspective of the above scholars, this paper intends to discuss the relationship between higher education and economic growth from the perspective of quantitative analysis, and for the first time, research whether the relationship between the two is true or not. The idea of the analysis is to follow the logical relationship of the cause before the result and the result, and to first make a Grainger causality test on the development of higher education and the economic growth. If there is a causal relationship between the two, the data stationary and cointegration test, in the inspection to ensure that the model is based on the true regression model, to further establish the 
error correction model, to discuss the long-term equilibrium and short-term dynamic relationship adjustment.

\section{The Grainger Causality Test of the Development of Higher Education and Economic Growth}

Considering the availability and representativeness of the index, we have chosen the gross enrollment rate of higher education as the index of higher education development since the reform and opening to the outside world, which is recorded as R. The economic growth indicators were selected from 1978 to 2002 the gross domestic product (GDP), and 78 years for prices to be adjusted to eliminate the impact of inflation. In addition, we add the income index of the same period to the economic growth index, which is recorded as I. Actually, we join the income of residents in order to make use of the transitivity of causality and add an auxiliary variable to identify the causal relationship between the development of higher education and economic growth. In the following analysis, it can be found that it is not only necessary to join this variable, but also has a strong explanatory power for the development of higher education.

Table1 Granger causality test results

\begin{tabular}{|c|c|c|c|c|}
\hline Causality type & Original hypothesis & F statistics & P value & conclusion \\
\hline \multirow{2}{*}{ G and R } & G is not a Granger cause of R & 3.66274 & 0.04628 & \multirow{2}{*}{$\mathrm{G}<=>\mathrm{R}^{* *}$} \\
\cline { 2 - 4 } & R is not a Granger cause of G & 4.43690 & 0.01572 & \\
\hline \multirow{2}{*}{ G and I } & G is not a Granger cause of I & 1.19761 & 0.32486 & \multirow{2}{*}{$\mathrm{G}<=>\mathrm{I}^{*}$} \\
\cline { 2 - 4 } & I is not a Granger cause of G & 2.93953 & 0.07858 & \\
\hline \multirow{2}{*}{ I and R } & I is not a Granger cause of R & 1.19761 & 0.32486 & \multirow{2}{*}{$\mathrm{I}<=>\mathrm{R}^{* *}$} \\
\cline { 2 - 4 } & R is not a Granger cause of I & 4.60298 & 0.02429 & \\
\hline
\end{tabular}

Note: ** indicated that the level of $5 \%$ was significant, * indicated that the level of $10 \%$ was significant.

Grainger causality test thought is that if $\mathrm{A}$ is $\mathrm{B}, \mathrm{A}$ in $\mathrm{B}$, in the regression model into A time-delay terms in A lag coefficient should be statistically significant, and can improve the explanatory ability of the model. That is, the hypothesis model is:

$$
\mathrm{y}_{1}=\sum_{i=1}^{\mathrm{k}} \alpha_{\mathrm{i}} \mathrm{y}_{\mathrm{t}-\mathrm{i}}+\sum_{\mathrm{i}=1}^{\mathrm{k}} \beta_{\mathrm{i}} \mathrm{X}_{\mathrm{t}-\mathrm{i}}+\mu_{\mathrm{t}}
$$

The primary hypothesis was Grainger $x_{t}$ instead of $y_{t}$, which is $H_{0}: \beta_{i}=0, i=1,2 \wedge \wedge \mathrm{K}$. Construct $F$ statistics as formula 2:

$$
\mathrm{F}=\frac{\left(\mathrm{RSS}_{\mathrm{r}}-\mathrm{RSS} \mathrm{u}_{\mathrm{u}}\right) / \mathrm{k}}{\mathrm{RSS}_{\mathrm{u}} / \mathrm{T}-\mathrm{n}}
$$

The results of Grainger test for R, G and I are shown in Table 1.

From the above analysis, we can see that $R$ is not the Grainger cause of $G$, and $G$ is the Grainger reason of $\mathrm{R}$. This is largely due to the fact that economic development is often preceded by education. Therefore, Grainger's causal test shows that economic growth is the cause of higher education, and negates the proposition that higher education development precedes economic growth. But this is only the discussion of the relationship between the two from the perspective of statistical test. In order to further explain the long-term equilibrium and short-term dynamic relationship between them, we use ECM (error correction model) for further analysis.

\section{Cointegration of the Development of Higher Education and Economic Growth}

Most of the economic data are no stationary data and cannot be used directly to establish regression models. If non - stationary data is used to model, it is very easy to produce "false regression" problem. 
In order to avoid "false regression" and reveal the true relationship between variables, the no stationary variable must be cointegration test.

Cointegration means: if the time series vector $\mathrm{y}_{\mathrm{t}}\left(\mathrm{y}_{1 \mathrm{t}}, \mathrm{y}_{2 \mathrm{t}} \Lambda \Lambda \mathrm{y}_{\mathrm{nt}}\right)$ of each component is I (d) series, $\alpha\left(\alpha_{1} \Lambda \Lambda \alpha_{N}\right)$, the $Z_{t}=\alpha^{*} y^{\prime}, b>0$. It is considered that the sequence YT is cointegration of $(d, b)$ order. The economic significance of cointegration analysis is that for two variables with their own long-term fluctuation rules, if they are cointegration, there is a long-term equilibrium relationship between them.

The cointegration test model for $\mathrm{y}_{\mathrm{t}}\left(\mathrm{y}_{1 t}, \mathrm{y}_{2 \mathrm{t}} \Lambda \Lambda \mathrm{y}_{\mathrm{nt}}\right) \mathrm{N} \mathrm{I}(\mathrm{d})$ vector time series. If there is $\mathrm{a}$ cointegration relationship between the $\left\{\mathrm{y}_{\mathrm{t}}\right\}$ components, there is a $\mathrm{y}_{\mathrm{it}}=\alpha_{0}+\alpha_{\mathrm{y}}{ }_{\mathrm{t}}{ }^{+}+\mu_{\mathrm{t}}$. If the estimation error $\mu_{\mathrm{t} .}$ is stationary, if $\mu_{\mathrm{t}}$ is stationary, then there is a cointegration relationship between the variables, and its retrospective regression model is true. On the other hand, there is no cointegration relationship between variables, and the model is "false regression". Because the $\mu_{\mathrm{t}}$ here is obtained based on the estimation equation, its distribution is different from the general stationary test distribution.

The cointegration test we adopt is EG test. In order to clearly describe the characteristics of the data, we first describe the statistical analysis of G, R and I, and draw their growth curves.

\section{Statistical Analysis of Data Description}

Table 2 GRI description statistics table

\begin{tabular}{|c|c|c|c|}
\hline Parameter name & $\mathrm{G}$ & $\mathrm{R}$ & $\mathrm{I}$ \\
\hline Average value & 1300.617 & 767.9621 & 143.987 \\
\hline Maximum value & 3015.890 & 2414.670 & 3679.234 \\
\hline Minimum value & 362.4100 & 259.0000 & 615.0000 \\
\hline Standard deviation & 833.8129 & 553.5773 & 826.3922 \\
\hline Skewness & 0.648577 & 1.811053 & 1.282686 \\
\hline Kurtosis & 2.123169 & 5.438340 & 3.791163 \\
\hline Growth rate & $115.16 \%$ & $112.41 \%$ & $112.67 \%$ \\
\hline
\end{tabular}

From the growth trend chart of the three, we can see that since the reform and opening up, G, R and I have increased exponentially, and their growth steps are almost the same. The average growth rate of 15 years is $115.16 \%, 112.41 \%$ and $112.67 \%$, respectively. With 93 years as an inflection point, the growth rate of the three has been greatly accelerated. 90 years ago, the deviation of $\mathrm{G}$ and I was small, and then began to increase. However, after 98 years, the gap between them began to decrease. It seems that there is a pull that makes the three partners move normally.

\section{Test on Stability of G, R and I}

In previous studies, almost all ignored the stability test of higher education and economic growth data, and directly established the model. Stability test is an important tool to avoid "false regression" and to find the true relationship between data. We used unit root test to test the stability of G, R and I.

Unit root test in the form of:

$$
\begin{aligned}
& \Delta y_{t}=\mu+\alpha t+\rho_{y_{t-1}}+\theta_{i}^{k_{1}} \Delta y_{t-i}+\varepsilon_{t} \\
& \Delta y_{t}=\mu+\rho_{y_{t}-1}+\sum_{i=1}^{k} \theta \rho_{y_{t}-i}+\varepsilon_{t} \\
& \Delta y_{t}=\rho_{t_{t-1}}+\sum_{i=1}^{k} \theta_{i} \Delta y_{t-i}+\varepsilon_{t}
\end{aligned}
$$

By ordinary least squares t statistic regression parameters calculated, subject to a Wiener process, can be directly used for the hypothesis testing, but with the Monte Carlo method given by ADF test critical values for several statistics, we use $r=\rho /$ se $(\rho) . \tau<$ ADF critical value then reject the null hypothesis, namely $\mathrm{y}_{\mathrm{t}}$ stable. On the other hand, $\mathrm{y}_{\mathrm{t}}$ is no stationary. The difference term of $\mathrm{y}_{\mathrm{t}}$ is repeated test until smooth. If the $\mathrm{D}$ order difference of $\mathrm{y}_{\mathrm{t}}$ is stable, then $\mathrm{y}_{\mathrm{t}}$ is $\mathrm{d}$ order integer, that is, $\mathrm{y}_{\mathrm{t}}$ $\sim$ I (d). 
Using the AIC and SC criteria, the ADF test equations of G, R and I are all lagging. According to the order from the unconstrained to the gradual increase of the constraint conditions, the three indexes are tested by different forms of test equations. It is proved that G, R and I are all 1 order mono - whole, that is, I (1) process. The results are shown in Table 3.

Table 3 ADF test of the single whole order of G, R and I

\begin{tabular}{|c|c|c|c|c|c|c|}
\hline \multirow{2}{*}{ Symbol } & \multicolumn{6}{|c|}{ ADF test difference order } \\
\cline { 2 - 7 } & Difference order & $\mathrm{k}$ & $\mathrm{t}$ & $\mu$ & $\tau$ value & 95\% Critical Value \\
\hline LG & 1 & 1 & 0 & 0.05553 & -3.95908 & -3.0038 \\
\hline LR & 1 & 0 & 0 & 0 & -2.19385 & -1.9566 \\
\hline LI & 1 & 1 & 0 & 0.05597 & -4.595175 & 2.9969 \\
\hline
\end{tabular}

\section{Cointegration Test of $\mathbf{G}, \mathbf{R}$ and $I$}

According to the previous Grainger causality test, the cointegration regression model is $R_{t}=c+a$, $\mathrm{G}_{\mathrm{t}}=\alpha_{2} \mathrm{l}_{\mathrm{t}}+\mu_{\mathrm{t}}$. The results of the modeling are as follows:

$$
\begin{gathered}
\mathrm{LR}=-1.440714781+0.4850247402 * \mathrm{LG}+1.739717609 * \mathrm{LI} \\
(-3.04939) \quad(-4.05367) \\
\mathrm{R}^{2}=0.92784, \mathrm{DW}=1.345, \mathrm{~S} . \mathrm{E}=0.162649, \mathrm{~F}=141.4393
\end{gathered}
$$

(Note: the number in parentheses is t value)

\section{The Establishment of Four, G, R, I Error Correction Model (ECM)}

The cointegration relationship tells us two aspects of the information. First, the model of the regression between higher education and economic growth is true. Secondly, there is a long-term equilibrium relationship between higher education and economic growth. When their trajectories deviate, there is always a force that pullback them back to the equilibrium position. The ECM model is a dynamic model that portrays this power.

In the view of the Hendry School, any ECM model can be derived from the autoregressive distribution lag model. If there is an ADL (M, M, N) model, then the model can always be deformed, and a ECM model of the M-1 order error correction term can be obtained. The general representation of the model is:

$$
\Delta y_{t}=\sum_{i=1}^{m-1} \Delta y_{t-i}+\sum_{i=0}^{m-1} \sum_{j=1}^{n} \Delta x_{j t-i}+k E C M_{m}+S_{t}
$$

According to the Grainger theorem, the first order single variable with cointegration relationship must establish an error correction mechanism. By the unit root test, we have proved that $G, R$ and I are both I (1), and have cointegration relationship. Therefore, a ECM model can be built between G, R, and I.

The error correction model is introduced by introducing the lag phase $\mathrm{u}_{\mathrm{t}-1}$ and LG, LR and LI first order differential variables $\mathrm{u}_{\mathrm{t}}, \Delta \mathrm{LG}_{\mathrm{t}}, \Delta \mathrm{LR}_{\mathrm{t}}$ and $\Delta \mathrm{LI}_{\mathrm{t}}$ to form an error correction model.

$$
\begin{aligned}
\Delta \mathrm{LR}= & 0.10556+0.57709 * \mathrm{LR}(-1)+1.06065 * \mathrm{LG}+0.66795 * \mathrm{LI}-0.64554 * \mathrm{E}(-1) \\
\quad(-2.053)(2.9558) & (3.724) \\
\mathrm{R}^{2}= & 0.7844, \mathrm{DW}=2.1005 \text {, S.E }=0.18727
\end{aligned}
$$

(Note: the number in parentheses is t value)

It can be seen from the calculation results that the coefficient of the error correction term $\mathrm{ECM}^{\mathrm{t}-1}$ is negative and is statistically significant. The change of error correction is significantly affected, when the change of $\Delta \mathrm{LG}_{\mathrm{t}}$ is greater than the equilibrium position, in the error correction mechanism to enable LG to smaller direction; when the change of LG is less than the equilibrium position, error correction mechanism will make the next LG increase. Through the adjustment of the balance error of 
the last period, it will always keep higher education and economic growth and the income of residents to keep on a balanced track.

\section{Conclusion}

Through the above empirical analysis, we draw the following conclusions:

1 economic growth is the cause of accelerating the development of Higher Education

We found that by Grainger causality test, GDP model development lag of higher education ability to explain in more than $90 \%$, and the coefficients are statistically significant, which demonstrates the relation between higher education and economic growth is a one-way causal relationship, economic growth is the cause of the development of higher education. It is worth noting that the Grainger causality test is based on the idea of prior to the fruit. Our conclusion is not to deny the research of previous scholars and to deny the significance of higher education to economic growth. In fact, since China's reform and opening up, economic growth has developed ahead of higher education. The main reason is that China's higher education didn't introduce the market mechanism until the middle of 90s. Its development expenditure is largely dependent on national finance. In this way, its development path is slower than economic growth.

2 there is a real long-term equilibrium and short-term dynamic relationship between higher education and economic growth and residents' income

By unit root test, we find that the data are all first order differential stationary at the critical value of $5 \%$. In order to avoid the trap of "false regression" and make the analysis more rigorous, we have done a cointegration test. The test results show that there is a cointegration relationship between the development of higher education and the increase of economic growth and the increase of residents' income, and on this basis, an error correction model is established. From the analysis, we can conclude that there is a ratio equilibrium relationship between the development of higher education and the economic growth and the income of the residents in China. The level of economic development and the income level of the residents have the corresponding level of higher education. In the final analysis of this equilibrium, the development of higher education is always inseparable from the need of economic development. The need for high quality talents and the increase of financial and private funds will accelerate the development of higher education. From the error correction model, we also find that economic growth has the greatest impact on higher education, and its short-term multiplier has reached about 1 . We think this again shows that economic growth plays an important role in speeding up higher education. It also responds to the fact that the power of private investment is far less than from other investment channels (mainly financial investment).

Impact strength.

3 speed up the pace of market-oriented reform of higher education and establish the operating mechanism to meet the requirements of economic development

Using the Grainger causality test, we conclude that the economy is the Grainger reason for the development of education and refuses the hypothesis that higher education promotes economic development. From the perspective of our empirical research, the higher education in China has gone through a period of rapid development in the past 78 years, but despite the accumulation of time, the pulling effect of higher education development on economic growth has not yet been effectively released. There are two main reasons for the lack of the effect of higher education on economic growth

1 ) is to set up a higher education system is not reasonable, not many professional courses to meet the needs of economic development; in the process of teaching and ignore the cultivation of students' practical ability; scientific research or education achievements is slow, because the conversion delay is too long, the original is the economic value of fruits lost its economic significance.

2) the channel of transmission of higher education to promote economic growth is not smooth. The role of education in the economy is mainly reflected by the final product of its output: human capital. Therefore, to reform the employment system, so their ability, higher education can really 
promote economic growth. At present, speeding up the pace of the reform of higher education market is the key to the full play of the role of higher education.

\section{Reference}

[1] China Statistical Yearbook 2002[M]. Beijing: China Statistics Press, 2003.

[2] fanxianzuo. Economics of education.[M]. Beijing: People's education press, 2001.5.

[3] display. A worldwide subject of market economy and higher education [M]. Beijing: People Education Press, 1999-3.

[4] Qin Baoting. Education and economic growth [M]. Nanchang: Jiangxi Education Press, 1992.

[5] Ceng Manchao, Xue Boying, Qu Heng, Trevor compiled. The western educational economics [M]. Beijing: Beijing Normal University press, 1990.(in Chinese)

[6]Roger Garrett, Education and Development. CroomHelm,1984.

[7]Lyman A. Glenny, Funding, Higher Education: A Six-Nation Analysis. Pracger Publishers. U.S.A. 1979.

[8]Martin Trow, American Higher Education-Past, Present and Future. Studies in Higher Education. Vol.14, No.1,1989. 